\title{
Reflection on the Translation Debates in History: Thinking Out of the Dichotomies
}

\author{
Lili Xie $^{1}$ \\ ${ }^{1}$ Hongkong Baptist University, Sichuan, China \\ Correspondence: Lili Xie, Hongkong Baptist University, Apartment of the local tax department, Yahou Street \\ No.5, Jiajiang county, Leshan, Sichuan Province, China.
}

Received: February 24, 2019

Accepted: March 24, 2020

Online Published: April 13, 2020

doi:10.20849/aes.v5i1.735

URL: https://doi.org/10.20849/aes.v5i1.735

\begin{abstract}
With an overview of translation history, from the ancient Rome to modern times, from Western countries to Eastern countries, there were heated debates over translation principles or strategies, most of which revolved around the matter of literal translation or free translation. Many famous theorists advocated that literal translation was preferred than free translation; others disapproved that. However, either side failed to have a comprehensive prospective towards translation, because translation is actually a complex framework, involving many elements worth our attention. To do translation studies, the theories shall break the irrational mindset and jump out of dichotomies to gain an overall and objective understanding of translation.
\end{abstract}

Keywords: literal translation, free translation, source text, target text, text type, translation strategies

\section{Translation Debates in History and Their Limitations}

Western translation theory went back to ancient Rome, when Cicero argued that a translator shall act as an orator rather than an interpreter. At that time, there were two groups: the first one included Cicero, Horace, Quintilianus, etc. who advocated free translation; the other represented by Philo Judaeus, St. Augustine, who engaged in Bible translation, insisted the translators of the Bible were inspired by the God, thus they shall obey the content and the style of the original. The conflicts between the two groups unveiled a seemingly fundamental question: shall translators adhere to the original or reproduce a much better translation in spite of some adjustments? To put straightly, this was the divergence between literal translation and free translation.

The dispute between literal translation and free translation ran through many generations of translators, also through Chinese history of Sutra translation, for instance, the dispute over Wen and Zhi over the sutra translation.

In the 19th century England, two theorists: Francies Newman and Matthew Arnold had a debate on translations of Homer's Epic - Newman, as a classicist, translated texts with old English, which could thus highlight the "foreignness" of the source text; while Arnold criticized Newman's way of translation. This noted debate triggered another several questions: firstly, what shall be retained in the translation of ancient literary works - the diction, the syntax, the style of the source text or the characteristics of the author's writing, the flavor and the aesthetic value of the source text? Secondly, shall the target text be read like a translation or not? In today's view, this was a debate between domesticating translation and foreignizing translation proposed by Lawrence Venuti (1995).

However, before answering the questions above, we must clarify what is translation? In 1964, Eugene A.Nida published Towards a Science of Translating, in which he stated that translation is a science. Then, Newmark concluded in his papers that translation can be a craft, a science and an art. Indeed, translation is a craft with which we communicate with foreigners and exchange opinions with them; it is craft for teachers to help students learn a foreign language and to test students' mastery of a foreign language. Also, translation is not just a simple craft, it is also a science and this is the starting point for translation studies. Meanwhile, although there are principles, norms, techniques, etc. in translation which depict a "guideline" for translators to do translating work, no one dares to point out there is a "right" translation version for a specific source text. This is because translation is also an art. The combination of the three characteristics in translation determines it is a complex discipline. 
Therefore, the dispute between literal translation and free translation or between domesticating translation and foreignizing translation can't be simply settled. Translation, as a craft, a science and an art, generates multidimensional questions, those are not supposed to be solved with dichotomies - they are not "yes" or "no" questions. Instead, the questions shall be dealt with within a rigorously logical framework.

\section{Contemporary Translation Theories and Their Advancements}

Contemporary translation theorists come to realize the logic within translation studies from different perspectives. For the linguistic translation theorists, they emphasize the close connection between linguistics and translation. One of them is Katharina Reiss, who proposed text-typology in translation based on Karl Buhler's functions of language, stating that texts can be divided into informative text, expressive text and vocative text (1971); she suggested that "specific translation methods according to text type" (1976). Another theorist Peter Newmark put forward "semantic translation" and "communicative translation" (1981) and proposed "different text types shall be translated with different translation methods". This is a promising idea that the source texts fall into different types, the translators thus shall deal with texts according to its types, for example, communicative translation is normally be used when translating advertisement; semantic translation can be used when translating literary works.

Moreover, for the theorists of Descriptive Translation studies (DTS), they describe translation phenomena and probe into different translation methods or problems. They refuse to give a guideline for the translators to obey, because they realize there are many limitations or external factors, such as the patronage, the canon in poetics and the ideology, etc. which exert influences on the decisions of translators.

Justa Holz-Manttari proposed the model of translational action (1984). The model of translation action involves the initiator or commissioner the ST (source text) produce, the TT (target text) producer, the TT user and the TT receiver. Translators are not only deal with the source text only, they work within this framework.

\section{Translation as a Craft, a Science and an Art}

Translators deal with different types of source texts, work for different clients or target readers and under different limitations. Moreover, they translate texts from various countries, cultures, times. How could there be an invariant guideline for them to obey? -we shall analyze different translation issues according to different cases.

An instance "turn a deaf ear", for example, means that one ignores another's speech and pays no attention to it. Then, how do we translate this phrase? A college student of translation may figure that four-character idioms are preferred in Chinese literature and thus may translate the source text as “置若罔闻”. To use four-character idioms in Chinese translation is a common technique taught in translation classes. However, what if the phrase is extracted from a comedy? Then it can be translated as “左耳朵进, 右耳朵出” or “把别人的话当耳旁风”.

In translation classes, students have learnt many translation techniques and with these techniques they have conducted practices. Then, the teacher would grade their works to ensure the students know what they can enhance in their translations. Certainly, practice is a favorable way to improve translation ability. The students can benefit from the process of translation and revision. As the they revised their translations again and again, they gradually learned how to make the "right" work. But what is a "right" translation?

In Chinese translation classes, students learn techniques, including repetition, amplification, omission, conversion, division, combination, negation, etc. Also, they learn translation strategies: literal translation and free translation; domesticating translation and foreignizing translation. However, they usually fail to know when to use these techniques or strategies.

Translation techniques and strategies are operated under translation principles. Yet, Chinese students know too much about techniques while they know little about principles and theories. If a Chinese translation student are asked: how do you understand translation principles? He or she may answer with "Xin", "Da" and "Ya", which is proposed by Yan Fu in his preface of the translation of Evolution and Ethics in 1897. The word "Xin" refers to faithfulness, "Da" to expressiveness and "Ya" to elegance, which means that the target text firstly should be faithful to the original, and then it should be fluent and elegant. It is certainly a right principle, but it is not enough.

Firstly, what is not to be advocated here is that we put a uniform standard on every text or we presuppose there were perfect translation solutions for translators to deal with any kind of texts. If the class went on like that, students would never know what translation is as an art. Any question belonging to art, like music, poetry, painting has more than one answer. The composers write different tunes on the same stave; the poets create haikus, sonnets, epics with the same pen; the painters draw sketching, oil painting, Chinese ink painting on the 
same paper. Translators, like artists, can compose different translations with their own characteristics. This is art, and art is changeable.

Secondly, while we primarily admit that translation is an art, we should have it in our mind that it is not only an art, also a craft and a science. Craft means it can be mastered with some knacks and mastering it can bring practical significance. So how can we master this craft and use it logically?

The translation procedure is just like interior design or house decoration. At the beginning, the designer comes to the site to observe the space, the location, the layout of the house. Then, according to these features and the house owner's plan, the designer draws pictures on the computer, in which he or she divides the house into several independent functional regions and chooses a style, maybe North-Europe style or classical style. At last, the designer begins to pay attention to the decoration of furniture, the color of wall paper and ceramic, etc.

When a source text is given to a translator, it is an unfurnished house. The commissioner or the initiator of the translation is the house owner, so the translator is the designer. The designer observes the house as the translator analyzes the source text, after which the translator will have a general idea about the source text and a determined direction for the translation. Then the translator, like the designer, starts to draw a draft of the whole project. He or she may know what strategies can be applied in the translation and according to these strategies, what techniques can be used to improve the translation.

The famous translation of L'Amant by Wang Daoqian is a notable case. There are several problems worth discussion: the source text, the author, the readers, and the translator's strategies and techniques to deal with these problems. The literary genre of the source text is literary novel or belles-lettres. It tells an impressive and tragic love story between a poor young French girl and a rich Chinese young man. When they encountered each other by the Mekong River in Vietnam, they fell in love despite their racial differences and wealth gap. As for the author, Marguerite Duras, she is a romantic woman all through her life and the themes of her books are mostly related to the pursuit of love. Her writing style is deep and full of tension, and most importantly, it is unique. She doesn't tell stories in a chronological order, she just records conversations, describes her situation and recalls things in the past in a casual way, which seems like keeping a diary. Actually, her mixed feelings were hidden behind those simple words, so Duras is known as one of the most impenetrable writers in world literature. The difficulty in translation in terms of the characteristics of the source text and the author lies mostly in understanding and transferring those feelings.

As for the readers of the book, they are possibly educated enough to have aesthetic tastes in literature; romantic enough to hold beliefs in love and sensitive enough to empathize with the complex feelings. Therefore, considering the readers, there are two main translation difficulties: firstly, the target readers require a translation of high quality in writing for their educational background and aesthetic preference; secondly, what they value in this book is the sense, feelings, atmosphere, romantic and poetic elements created by the author but it is difficult for translator to retain those factors in his translation because they are too illusory and difficult to catch.

Wang is a great translator. He understands the source text and knows the intention of the author. More importantly, he transfers it into fluent and graceful Chinese. For instance, the famous excerpts from L'Amant--« ... j'aimais moins votre visage de jeune femme que celui que vous avez maintenant, dévasté.» is translated by Wang Daoqian as “与你那时的面貌相比, 我更爱你现在备受摧残的面容。” The English translation is "Rather than your face as a young woman, I prefer your face as it is now. Ravaged." Both English and French belong to Indo-European languages and they share some similarities, so the English translation in this sentence changes little so as to be close to the original. However, there is a relatively huge difference between Chinese and French. In the source text, the word "dévasté" (摧毁) is separated from the whole to make an emphasis, but the syntax of the original is not in accordance with linguistic habits of Chinese. Thus, the translator changes the word order and rearranges the syntax. And he translates the word "dévasté” as “备受摧残”, a four-character Chinese idiom. These changes don't distort the meaning or sense of the original, at the same time they enhance the readability of the translation and make it idiomatic and poetic. This is an example that he applies the strategy of free translation to the text.

For another, Wang also applies domesticating translation strategy in the translation. Although the story is based on Vietnam in 1930s, which is a distant setting from us today, the readers can hardly feel foreignness as they appreciate the Chinese translation. This translation strategy is suitable for this translation, because it bridges the linguistic and cultural gaps between the source text and the target text, and in this way the target readers can receive the similar effects as the source text readers and the source text suffers few losses in this translation process. 


\section{Reflection and Conclusion}

As the case stated above, every source text has its own features and should be dealt with according to the actual situation. We refuse to put uniform rules on every translation, because there is never an absolute answer to it. Therefore, it is unfair to argue that literal translation is preferred to free translation because it adheres to the original or vice versa. We should bear it in mind that translation is a complicated discipline, which should be dealt with comprehensive outlook rather than dichotomy.

However, this is not to say it is meaningless to conduct researches on translation studies. Instead, translation is a craft and a science, which permits us to find out its logic to guide our principle or direction. Translation work is a logically rigorous framework, in which the translators coordinate the languages and cultures in source text with the target text. Working within the framework under kinds of constrains, the translators should learn how to find an optimal solution to each specific text.

In terms of the translation procedures, it can be divided into at least three procedures: before translation: the analysis; during translation: translating; after translation: revision and criticism. Firstly, the analysis is a three-dimensional problem, including the analysis of the source text, of the target text and of the translation direction. As for the source text, we shall ask several questions: what is the literary genre of the source text? What is the style of the source text? When has it be written? What is its background? Who is the author and what is his or her intention to write such a text? What effect does this source text bring to its readers? Then, we come to the target text: who is the commissioner or the initiator? What his or her intention to request the translation? Who are the target readers? What effect does the commissioner or the initiator want to bring to the target readers? Lastly, we come to the translation direction: what strategies are suitable for this translation? What techniques can be used in this translation? What is the translator's own writing style and how can it be combined with the source text to produce a translation of good quality? By analyzing the three-dimensional problem, the translator will have a general idea about the source text and a determined direction for the translation. Secondly, during the translation process, the translator deals with specific problems, for example, what is a proper translation unit? How can the source be more cohesive and coherent? How can the text read more idiomatic and fluent? How are the metaphors or neologisms translated? Those are specific translation problems worth further discussion. Lastly, revision and criticism are also explorable questions. However, they are simple question. Many people think that "back translation" is a good method to examine the target text, but it is not the case, because "faithfulness" or "accurateness" is not the primary concern or primary standard for all kinds of translations. Instead, we only need to grasp the key point: purpose - what is the purpose of this translation? For example, there is a famous advertisement “Your lips will know it. But your hips won't show it." It is translated in Chinese as “好吃看不见”. This is a chocolate advertisement. The Chinese version breaks through the original advertising form, using only five words, reflecting the characteristics that the chocolate is delicious but it doesn't cause obesity. Featuring in conciseness and readability, it is a good example in advertising. The purpose of an advertisement is to introduce the advantages of the good, draw attention of the consumers and persuade them to buy the good. In this case, "effect" becomes the primary concern, and the translation perfectly achieves the goal, so it becomes a successful case. Each translation has different purposes, and the revision process test whether the translation has reached its purpose.

\section{References}

André, L. (1992). Translation, Rewriting and the Manipulation of Literary Fame. Routledge.

Eugene, N. (2003). Toward a Science of Translating. Brill Academic Publishers.

Jeremy, M. (2008). Introducing translation Studies: Theories and Applications (2nd ed.). Routledge.

Lawrence, V. (1994). The Translator's Invisibility: A History of Translation. Routledge.

Peter, N. (1988). Approaches to Translation. Prentice Hall.

\section{Copyrights}

Copyright for this article is retained by the author(s), with first publication rights granted to the journal.

This is an open-access article distributed under the terms and conditions of the Creative Commons Attribution license (http://creativecommons.org/licenses/by/4.0/). 